\title{
DYNAMIC SPECTRUM ACCESS (DSA) DENGAN MEKANISME SPECTRUM SENSING BERBASIS PENDETEKSIAN KANAL DAN BANDWIDTH UNTUK EFISIENSI SPEKTRUM
}

\author{
Maria Ulfa Muthmainah ${ }^{1}$, Ardian Ulvan ${ }^{2}$, Hery Dian Septama ${ }^{3}$ \\ Jurusan Teknik Elektro Universitas Lampung, Bandar Lampung \\ Jl. Prof. Sumantri Brojonegoro No. 1 Bandar Lampung 35145 \\ 1email : eng.mariaulfa@gmail.com \\ ${ }^{2}$ email : ardian.ulvan@unila.ac.id \\ 3email : hery@unila.ac.id
}

\begin{abstract}
Abstrak - Perkembangan teknologi yang semakin pesat dan bertambahnya permintaan akses layanan yang semakin cepat menyebabkan kebutuhan spektrum meningkat. Pada mekanisme Static Spectrum Access (SSA) meningkatnya kebutuhan spektrum tidak diimbangi dengan alokasi spektrum yang ada sehingga terdapat kanal yang tidak digunakan (idle) yang menyebabkan spektrum perlu diefisiensikan. Cara untuk mengelola spektrum agar lebih efisien dapat dilakukan dengan prinsip Dynamic Spectrum Access (DSA). Mekanisme spectrum sensing berbasis pendeteksian kanal dan bandwidth menjadi bahasan dalam penelitian ini. Pada penelitian ini penentuan kanal idle ditentukan dengan algoritma pendeteksian kanal dan bandwidth. Perhitungan dilakukan dengan menghitung parameter pendeteksian yaitu daya transmit. Besar daya threshold (Pth) dibandingkan dengan besar daya noise (Pnoise). Jika daya threshold lebih besar dari daya noise (Pth > Pnoise) maka kanal idle dinyatakan terdeteksi, sementara sebaliknya kanal idle tidak terdeteksi. Hasil perhitungan menunjukkan bahwa kanal idle terdeteksi pada keseluruhan bandwidth apabila user lain terdeteksi dengan bit rate yang rendah. Bandwidth $5 \mathrm{MHz}$ memiliki ketersedian kanal idle lebih besar dibandingkan $3 \mathrm{MHz}$, dan 1,4 MHz. Dengan terdeteksinya kanal idle pada suatu bandwidth menjadikan penggunaan spektrum dengan mekanisme spectrum sensing menjadi efisien. Jarak maksimum user untuk dapat melakukan pendeteksian kanal idle sejauh 250 meter $(n=3)$ dan 15 meter $(n=4)$.
\end{abstract}

Kata kunci - efisiensi spektrum, DSA, kanal idle, spectrum sensing.

Abstract - The fast development of technology and the increase of service access demand affect the increase of spectrum requirement also increases. In the Static Spectrum Access (SSA) mechanism, the requirement is not equal to available spectrum allocation, thus there are channels which are not used (idle) which allow the spectrum to be more effieciently allocated. The method to overcome the scarcity is by applying Dynamic Spectrum Access (DSA) mechanism. Spectrum Sensing mechanism based on channel and bandwidth detection is conducted in this research. In this research, the idle channel determination was determined by channel and bandwidth detection algorithm. The value of threshold power (Pth) is compared to the value of noise power (Pnoise). If threshold power is greater than noise power, idle channel will be declared as detected, otherwise channel idle will not be detected. The result of calculation show that idle channel is detected on the overall bandwidth if it is detected by another user at a low bit rate. $5 \mathrm{MHz}$ bandwidth has the availability of idle channel greater than $3 \mathrm{MHz}$, and 1,4 $\mathrm{MHz}$. Detection of idle channel at a bandwidth makes use of spectrum to be more efficient. The user maximum distance to detect the idle channel is as far as 250 meter $(n=3)$ and 15 meter $(n=4)$.

Keywords : Spectrum Efficiency, DSA, idle channel, spectrum sensing. 


\section{PENDAHULUAN}

Frekuensi merupakan sumber daya alam yang disediakan oleh alam dan penggunaannya terbatas. Rentang frekuensi yang digunakan dalam dunia telekomunikasi berkisar $300 \mathrm{KHz}-30$ $\mathrm{GHz}$. Alokasi rentang frekuensi ini disebut dengan spektrum. Pada mekanisme konvensional yaitu Static Spectrum Access (SSA) [1], spektrum akan dialokasikan secara statis oleh user baik untuk mengakses layanan ataupun tidak. Apabila spektrum tidak digunakan oleh user untuk mengakses layanan maka terdapat kanal yang tidak digunakan (idle) pada suatu bandwidth.

Saat ini perkembangan teknologi dan sistem komunikasi seluler sangat pesat seiring bertambahnya permintaan layanan akses yang semakin cepat. The $3 r d$ Generation Partnership Project (3GPP) mengembangkan jaringan nirkabel yang disebut Long Term Evolution (LTE). LTE menjanjikan kecepatan transmisi data yang lebih tinggi dan mendukung bandwidth yang besar yaitu mencapai $20 \mathrm{MHz}$ [2] dan $100 \mathrm{Mbps}$ untuk akses bergerak [3].

Peningkatan kebutuhan permintaan layanan yang cepat dan transmisi data yang tinggi menyebabkan kebutuhan spektrum meningkat. Mekanisme SSA tersebut menimbulkan masalah berupa kelangkaan alokasi spektrum. Hal tersebut menjadi penyebab alokasi spektrum perlu diefisiensikan.

Konsep radio kognitif membagi user menjadi dua kategori berdasarkan prioritas penggunaan kanal yaitu primary user (PU) dan secondary user (SU) [4]. Primary user (PU) merupakan user yang memiliki prioritas tinggi dalam penggunaan kanal, sedangkan secondary user (SU) merupakan user yang menggunakan kanal secara oportunistik. Pada radio kognitif, user equipment (UE) memiliki dua fitur yang membedakannya dengan radio konvensional, yaitu kemampuan kognisi dan kemampuan rekonfigurasi. UE secara aktif melakukan pengukuran untuk merasakan (sense) lingkungan sekitar radio, menganalisi informasi yang diperoleh (learn) dan memutuskan spektrum mana yang akan digunakan dan strategi transmisi yang akan digunakan (optimise) [5]. Konsep radio kognitif ini bekerja berdasarkan prinsip Dynamic Spectrum Access (DSA). Pada DSA, kanal akan dialokasi ke user sesuai dengan permintaan user dalam mengakses layanan. Mekanisme yang digunakan yaitu spectrum sensing. Pada spectrum sensing, SU dapat menggunakan kanal yang tidak sedang digunakan oleh PU (idle) sementara waktu. Apabila PU ingin menggunakan kanal idle tersebut, maka SU harus mencari alokasi spektrum yang tidak sedang digunakan lainnya. Terdapat tiga metode pada spectrum sensing, yaitu deteksi energi, matched filter, dan cyclostatinary feature [6]. Pada penelitian ini metode yang digunakan adalah deteksi energi sehingga pendeteksian kanal idle dilakukan dengan mendeteksi besar energi pada setiap bandwidth spektrum.

\section{SPECTRUM SENSING}

\section{A. Spectrum Sensing}

Spectrum sensing merupakan langkah utama pada radio kognitif untuk mencapai tujuan yaitu dapat memanfaatkan kanal idle dengan kemampuan kognisi untuk mengukur aktivitas elektromagnetik dan mengadaptasi paramater yang sesuai, seperti daya transmisi, modulasi, dan lain-lain. Kemampuan kognisi ini adalah kemampuan radio kognitif untuk merasakan lingkungan sekitar radio, menganalisis informasi yang ditangkap, dan memutuskan tindakan yang sesuai yang terbaik, spektrum mana yang akan digunakan. Kemampuan kognisi ini memungkinkan radio kognitif untuk terus menerus mengamati lingkungan di sekitar radio yang berubah secara dinamis agar menyesuaikan dengan rencana transmisi yang akan digunakan.

\section{B. Karakteristik Spectrum Sensing}

Menurut [7], Spectrum sensing didasarkan pada teknik deteksi sinyal. Deteksi sinyal dapat dapat dideskripsikan sebagai metode untuk mengidentifikasi keberadaan sinyal. Secara analitis, deteksi sinyal diformulasikan sebagai berikut:

H1 $\quad \mathrm{x}(\mathrm{n})=\mathrm{s}(\mathrm{n}) \cdot \mathrm{h}+\mathrm{w}(\mathrm{n}) \ldots \ldots \ldots \ldots \ldots \ldots(2.1)$

H0 $\quad x(n)=w(n) \ldots \ldots \ldots \ldots \ldots \ldots \ldots \ldots(2.2)$

Dimana, $\mathrm{x}(\mathrm{n})$ adalah sinyal yang diterima oleh $\mathrm{SU}$ yang ditransmisikan oleh PU, h adalah koefisien kanal, dan w(n) adalah Additive White Gaussian Noise (AWGN) dengan variasi $\sigma^{2}{ }_{\mathrm{w}}$.

H0 dan H1 merupakan hipotesis yang menunjukkan keadaan sensing untuk kondisi sinyal PU tidak ada maupun ada.

\section{PENDETEKSIAN KANAL IDLE}

Pada pendeteksian kanal idle digunakan algoritma pendeteksian kanal dan bandwidth. Parameter pendeteksian kanal dan bandwidth yang 
ditentukan adalah besar daya transmit suatu eNodeB. Daya transmit maksimum yang ditransmisikan oleh $e N o d e B$ dinyatakan dengan daya threshold (Pth). Daya threshold (Pth) dinyatakan sebagai batas pendeteksian kondisi kanal. Daya transmit yang dibangkitkan berdasarkan adanya kedudukan PU menggunakan kanal bandwidth dinyatakan sebagai daya noise (Pnoise). Pendeteksian kanal idle dapat dinyatakan dalam algoritma berikut:

01. Inisiasi Set Jumlah Kanal;

02. Set besar Bandwidth;

03. Menghitung Daya threshold (Pth);

$$
P t h=\frac{\left(\operatorname{Mmax}^{2}-1\right) \cdot N o W}{G t \cdot G r \cdot\left(\frac{\lambda}{4 \pi d}\right)^{2}}
$$

04. Menghitung Daya noise (Pnoise);

$$
\text { Pnoise }=\frac{\left(M p u^{2}-1\right) \cdot N o W}{G t \cdot G r \cdot\left(\frac{\lambda}{4 \pi d}\right)^{2}}
$$

05. Menentukan Kondisi Kanal; If (Pnoise < Pth)

Kanal Idle; else Kanal Tidak Idle ;

06. end

\section{MODEL MATEMATIKA}

Besar bandwidth yang digunakan untuk mengakses layanan dinotasikan sebagai W. Bit rate maksimum dinotasikan sebagai Mmax, sementara bit rate yang digunakan oleh $\mathrm{PU}$ dinotasikan sebagai Mpu. Besar Gain pada eNodeB maupun user dinotasikan sebagai Gt dan Gr. Spektrum frekuensi dinotasikan dalam $\lambda$ $(\lambda=c / f)$. Jarak user terhadap eNodeB dinotasikan sebagai d. Daya threshold dan daya noise PU dinyatakan dalam persamaan berikut [8]

$$
\text { Pth }=\frac{\left(\text { Mmax }^{2}-1\right) \cdot \text { NoW }}{\text { Gt.Gr. }\left(\frac{\lambda}{4 \pi \mathrm{d}}\right)^{2}}
$$

Pnoise $=\frac{\left(M p u^{2}-1\right) \cdot N o W}{G t \cdot G r \cdot\left(\frac{\lambda}{4 \pi d}\right)^{2}}$

Dimana, besar bit rate maksmimum pada suatu bandwidth dinyatakan sebagai berikut [9]:

Mmax = Jumlah RB x 12 x OFDMA symbol $x$ tipe modulasi (4.3)

\section{HASIL DAN ANALISA}

Hasil yang diperoleh berdasarkan algoritma pendeteksian di atas maka dapat dilihat pada gambar di bawah ini.

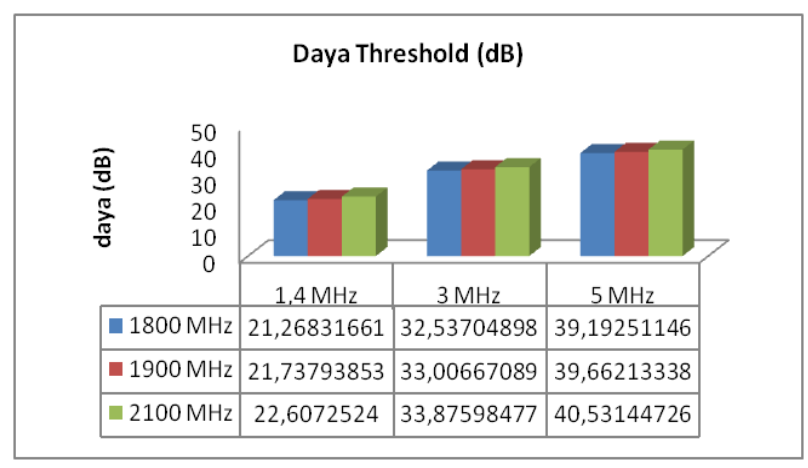

Gambar 1. Besar Daya Threshold pada tiap Spektrum

Pada gambar 1 menunjukkan hubungan bandwidth terhadap daya threshold (Pth) pada masingmasing spektrum frekuensi. Semakin besar bandwidth semakin besar daya threshold. Hal ini menunjukkan bahwa kapasitas kanal suatu bandwidth semakin besar bila bandwidth yang tersedia semakin besar.

\section{Perbandingan Pnoise dan Pth tiap Frekuensi (1,4 MHz)}

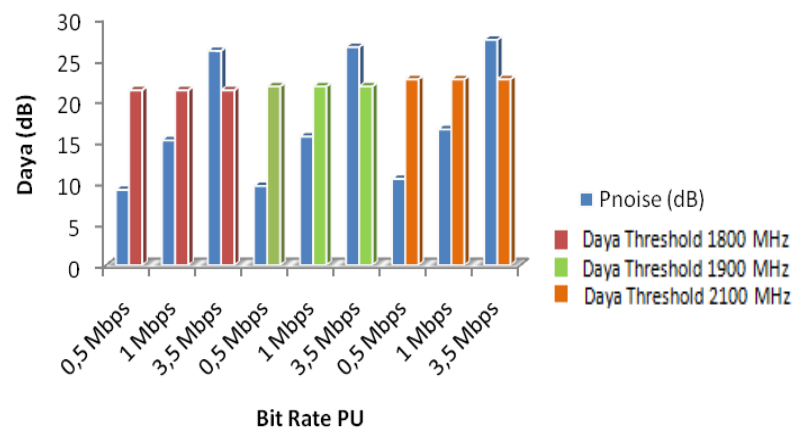

Gambar 2. Perbandingan Pnoise dan Pth Bandwidth 1,4 MHz tiap Spektrum Frekuensi

Perbandingan Pnoise dan Pth tiap Frekuensi (3 MHz)

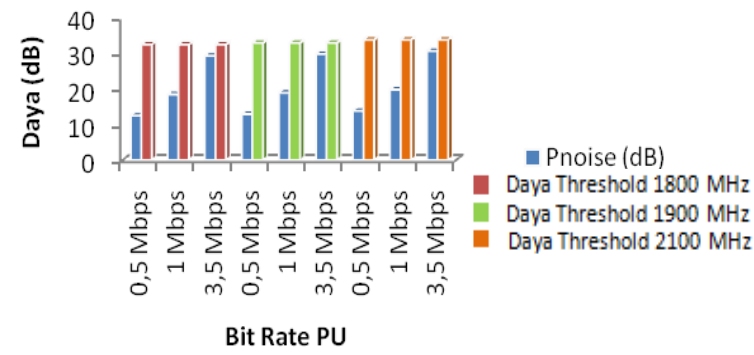

Gambar 3. Perbandingan Pnoise dan Pth Bandwidth 3 $\mathrm{MHz}$ tiap Spektrum Frekuensi 
Perbandingan Pnoise dan Pth tiap Frekuensi (5 MHz)

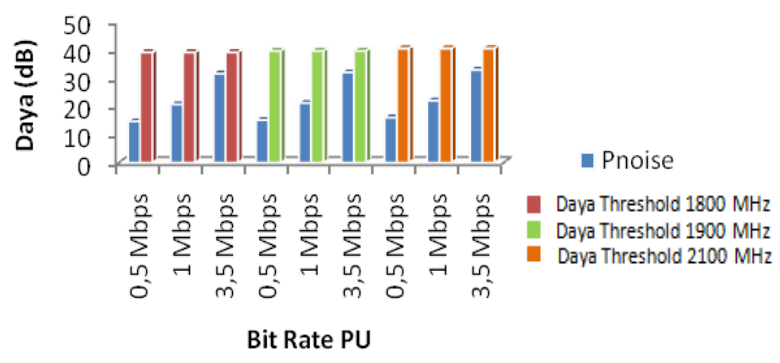

Gambar 4. Perbandingan Pnoise dan Pth Bandwidth 5 MHz tiap Spektrum Frekuensi

Gambar 2, gambar 3, dan gambar 4 menunjukkan perbandingan besar daya noise (Pnoise) terhadap besar daya threshold. Pada masing-masing bandwidth, PU diasumsikan menggunakan kanal bandwidth dengan bit rate sebesar 0,5 Mbps, 1 Mbps, dan 3,5 Mbps. Semakin besar PU menggunakan kanal pada suatu bandwidth, ketersediaan kanal idle semakin kecil. Seperti pada gambar 2, dimana pada bandwidth $1,4 \mathrm{MHz}$, kanal idle tidak tersedia jika PU menggunakan kanal bandwidth sebesar 3,5 Mbps. Hal ini karena PU telah menggunakan kapasitas maksimum bandwidth. Pada gambar 2 dan gambar 3, hasil menunjukkan bahwa kanal idle terdeteksi semakin besar pada bandwidth $5 \mathrm{MHz}$. Hal ini dapat dilihat saat PU diasumsikan menggunakan kanal dengan bit rate 3,5 Mbps, ketersediaan kanal idle pada bandwidth $5 \mathrm{MHz}$ lebih besar dibandingkan dengan $3 \mathrm{MHz}$.

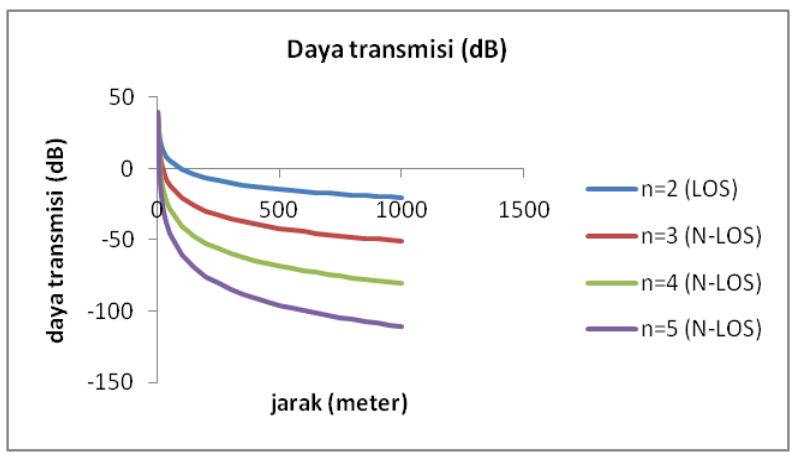

Gambar 5. Besar Daya transmisi yang diterima SU
Pada radio kognitif, user secara aktif melakukan pengukuran besar daya transmisi. Hasil yang ditunjukkan pada gambar 5 menunjukkan bahwa perubahan jarak menyebabkan daya transmisi mengalami penurunan sehingga daya minimum yang diperlukan untuk melakukan pendeteksian kanal idle tidak terpenuhi. Selain jarak, kondisi lingkungan jangkauan $e N o d e B$ menjadi faktor tambahan dalam pendeteksian kanal idle. Pada kondisi lingkungan LOS ditunjukkan pada $n=2$, dan kondisi N-LOS dengan efek shadowing pada $\mathrm{n}=3-5$. Besar dari efek shadowing yang ditimbulkan mengalami penurunan daya transmisi yang signifikan. Hal ini menyebabkan pada jarak tertentu, SU tidak dapat melakukan pendeteksian kanal idle. Jarak maksimum SU dapat melakukan pendeteksian kanal idle pada kondisi N-LOS sejauh 250 meter $(n=3)$ dan 15 meter $(n=4)$.

\section{SIMPULAN}

Berdasarkan hasil analisa mekanisme spectrum sensing, kanal idle dapat dideteksi dengan menggunakan algoritma pendeteksian kanal dan bandwidth. Ketersediaan kanal idle semakin besar jika bandwidth yang tersedia semakin besar, yaitu $5 \mathrm{MHz}$ dengan besarnya bit rate $\mathrm{PU}$ yang diasumsikan terdeteksi sebesar 3,5 Mbps. Kenaikan daya threshold (Pth) atau daya transmisi sebanding dengan besar bit rate, bandwidth, dan frekuensi. Namun demikian besar daya threshold dalam system harus dibatasi tanpa harus mempengaruhi besar bit rate, bandwidth, dan alokasi frekuensi yang digunakan. Pembatasan daya threshold ini dapat dilakukan melalui mekanisme modulasi high rate dan/atau meningkatkan besar gain pada antenna pengirim dan penerima. Jarak mempengaruhi pendeteksian kanal idle, dimana pada jarak tertentu SU tidak diizinkan untuk melakukan pendeteksian. Jarak maksimum SU dapat melakukan pendeteksian kanal idle yaitu 250 meter $(\mathrm{n}=3)$ dan 15 meter $(\mathrm{n}=4)$.

\section{DAFTAR PUSTAKA}

[1] M. Buddhikot, Milind. 2007. Unserstanding Dynamic Spectrum Access: Models, Taxonomy and Challenges. Proceedings of IEEE DySPAN 2007: Dublin.

[2] Lucent, Alcatel. 2009. The LTE Network Architecture. Strategic White Paper: Alcatel Lucent

[3] Nohrborg, Magdalena. 2014. LTE. http://www.3gpp.org/technologies/ keywords-acronyms/98-lte diakses pada 3 Mei 2014.

[4] ITU Radioo Regulations, International Telecommunication Union. Geneva. 2008.

[5] Yucek, T., Arslan, H. A Survey of Spectrum Sensing Algorithms for Cognitive Radio Applications. IEEE Comm. Surv. Tutorials 11(1), 116-130. 2009. 
[6] Mounika, Bodepudi, et al. 2013. Spectrum Sensing Techniques and Issues in Cognitive Radio. International Journal of Engineering Trends and Technology (IJETT) Volume4Issue4.

[7] Fatih, Refik. 2010. Spectrum sensing techniques for Cognitive radio systems with multiple Antennas. Electronics and Communication Engineering: Izmir Institute of Technology.

[8] Dharmatanna, Dewi S. 2014. Efisiensi Energi Pada Jaringan Long Term Evolution (LTE) Dengan Skema Radio Kognitif Dan Kooperatif Base Station. Bandar Lampung: Universitas Lampung.

[9] Umam Fahmi, Khotibul. 2014. Analisa Mekanisme Load Balancing Pada Fungsi Self-Organization Network (SON) Berbasis Long Term Evolution (LTE). Bandar Lampung: Universitas Lampung. 